\title{
Research on the Layered Rock Mass Excavation Relaxation Stability of Underground Caverns
}

\author{
Ying Zhang ${ }^{1,2}$, Heng Zhou ${ }^{1,2, a}$, Shengjie $\mathrm{Di}^{1,2}$ and $\mathrm{Xi} \mathrm{Lu}{ }^{1,2}$ \\ ${ }^{1}$ Northwest Engineering Corporation Limited, Power China, Xi’an, Shanxi, 710065, China \\ ${ }^{2}$ High Slope and Geological Hazard Research \& Management branch, National Energy and Hydropower Engineering Technology R\&D \\ Center, Xi'an, Shanxi, 710065, China
}

\begin{abstract}
In order to compare the influence of rock mass parameters weakening on the deformation and stability of excavation caverns in layered rock mass, based on power generation system caverns of a hydropower station, the stability and deformation of the caverns is analyzed. The results show that the mechanical characteristics of the structure surface play a major role in controlling the stability of caverns. And the displacement and yield zone value of plan 3, which adopt elastic-plastic softening model, are significantly larger than other two. The method which consider the residual strength of structure surface is more suitable for the excavation calculation of layered rock mass cavern.
\end{abstract}

\section{Introduction}

Rock masses are discontinuous, heterogeneous and anisotropic geological bodies composed of various weak structural planes. Due to the existence of layers, the layered rock mass not only anisotropy in deformation and strength, but also the failure mechanism and method are obviously different from other rock masses $[1,2]$. During the excavation of the cavern, the original stress equilibrium state of the rock mass was broken, and the rock mass deformation and strength parameters are significantly weakened. Generally, in elastoplastic numerical analysis, rock mass parameters are always constant during the excavation process. In order to analyze the stability of the excavation engineering more accurately, it is necessary to consider the strength parameters weaken of the rock mass in the numerical calculation.

The constitutive model is one of the important contents of rock mechanics research, and the commonly used constitutive models include elastic, nonlinear elastic, elastoplastic and rheological constitutive models [3]. The stress-strain relation curve of rock can be approximated as linear at the beginning, which is the elastic property. And when the strain increases beyond the linear deformation stage, the stress-strain relationship may present several different nonlinear conditions: ideal elastic-plastic, elastic-plastic hardening and elastic-plastic softening [4]. The ideal elastic-plastic model shows that the strain continues to increase while the stress remains unchanged. And the elastic-plastic hardening model shows that the strain can bear more stress after the strain increases, and the elastic-plastic softening model shows that the strength decreases gradually after the strain increases.
In this paper, based on power generation system caverns of a hydropower station, considering the rock mass and the structural plane residual strength after layered surrounding rock excavation, adopting the ideal elastic-plastic stress-strain softening model, the stability and deformation of the caverns is analyzed. It can provide reference for cavern excavation design in similar rock mass.

\section{Engineering situation and numerical calculation model}

The underground caverns of the power generation system are placed at the tail of the water conveyance system, and located in the low-mid geostress area (Table 1). The thickness of the overlying rock mass is about $300 \sim 480 \mathrm{~m}$, and the lithology is micro-weathered granodiorite with well-developed bedding. And fault passes through the caverns, the fault zone is filled with fragmented rocks and flaky rocks, with poor cementation.

Table 1. Measured In-situ stress

\begin{tabular}{cccc}
\hline$\sigma_{1}(\mathrm{MPa})$ & $\sigma_{2}(\mathrm{MPa})$ & $\sigma_{3}(\mathrm{MPa})$ & $\begin{array}{c}\text { Angle between } \sigma_{1} \\
\text { and horizontal } \\
\text { counterclockwise }\end{array}$ \\
\hline 6.88 & 5.68 & 3.49 & $121^{\circ}$ \\
\hline
\end{tabular}

The ideal elastic-plastic stress-strain softening model is shown in Figure 1. In the Mohr-Coulomb criterion [5]:

$$
H^{M C}\left(\sigma_{r}, \gamma^{P}\right)=\left(N\left(\gamma^{P}\right)-1\right) \sigma_{r}+Y\left(\gamma^{P}\right)
$$

Where $\sigma_{r}$ is the small principal stress and $\gamma^{P}$ is the plastic shear strain.

\footnotetext{
* Corresponding author: ${ }^{\mathrm{a}} 14276804 @ q q . c o m$
} 


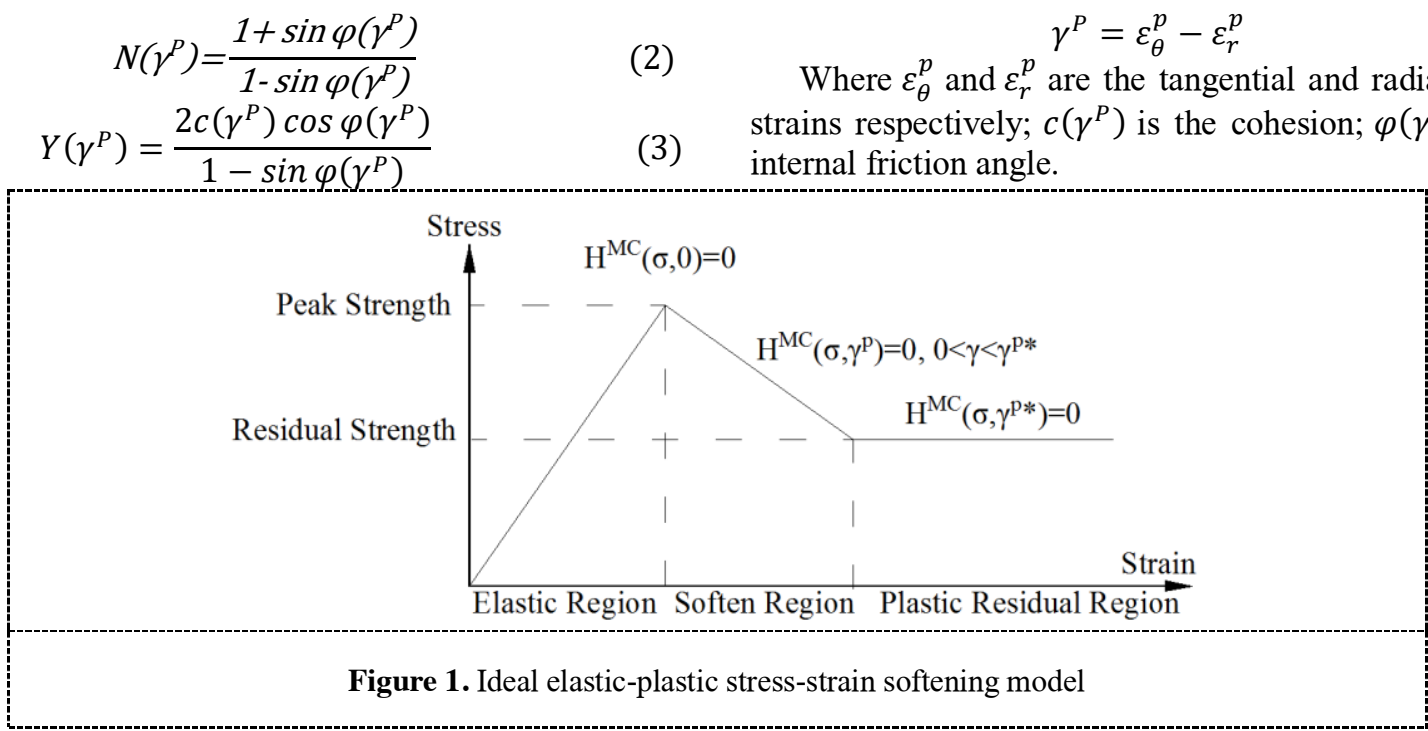

When the $\gamma^{P}$ is 0 , the surrounding rock is in the elastic region. $0<\gamma^{P}<\gamma^{P *}$, the surrounding rock is in the soften region. And when $\gamma^{P}>\gamma^{P *}$, the surrounding rock is in the plastic residual region, $\gamma^{P *}$ is the critical value.

According to the strain softening model, the strength parameter can be described by the strain softening coefficient:

$$
\omega\left(\gamma^{P}\right)=\left\{\begin{array}{cl}
\omega_{p}-\left(\omega_{p}-\omega_{r}\right) \frac{\gamma^{P}}{\gamma^{P *}} & 0<\gamma^{P}<\gamma^{P *} \\
\omega_{r} & \gamma^{P} \geq \gamma^{P *}
\end{array}\right.
$$

where $\omega$ represents the strength parameters of the surrounding rock, $\omega_{p}$ and $\omega_{r}$ are the peak and residual strength of surrounding rock respectively.
In order to compare the influence of rock mass parameters weaken on the deformation and stability of excavation caverns, the ideal elastic-plastic constitutive and elastic-plastic stress-strain softening relationship are selected in the calculation. And the elastic-plastic stressstrain softening relationship is applied in the rock blocks and structural planes to reflect weakening during excavation relaxation, the ideal elastic-plastic stress-strain softening model is shown in Figure 1. The physical and mechanical parameters of rock mass is shown in Table 2.

The Mohr-Coulomb slip constitutive model are adopted in the calculation, and the material parameters for structural planes is shown in Table 3 .

Table 2. Physical and mechanical parameters of rock mass

\begin{tabular}{cccccccc}
\hline $\begin{array}{l}\text { Rock } \\
\text { mass } \\
\text { types }\end{array}$ & $\begin{array}{c}\text { Bulk density } \\
\left(\mathrm{kN} / \mathrm{m}^{3}\right)\end{array}$ & $\begin{array}{c}\text { Modulus } \\
(\mathrm{MPa})\end{array}$ & $\begin{array}{c}\text { Poisson's } \\
\text { ratio }\end{array}$ & $\begin{array}{c}\text { Peak } \\
\text { friction } \\
\text { angle } \\
\left({ }^{\circ}\right)\end{array}$ & $\begin{array}{c}\text { Peak } \\
\text { cohesion } \\
(\mathrm{MPa})\end{array}$ & $\begin{array}{c}\text { Residual } \\
\text { internal } \\
\text { friction } \\
\text { angle }\left(^{\circ}\right)\end{array}$ & $\begin{array}{c}\text { Residual } \\
\text { cohesion } \\
(\mathrm{MPa})\end{array}$ \\
\hline Rock & 27 & 15000 & 0.28 & 48 & 1.0 & 39 & 0.8 \\
Fault & 25 & 4000 & 0.32 & 35 & 0.4 & 33 & 0.3 \\
\hline
\end{tabular}

Table 3. Mechanical parameters of structural planes

\begin{tabular}{ccccccc}
\hline $\begin{array}{c}\text { Structural } \\
\text { plane types }\end{array}$ & $\begin{array}{c}\text { Peak internal } \\
\text { friction angle } \\
\left({ }^{\circ}\right)\end{array}$ & $\begin{array}{c}\text { Peak } \\
\text { cohesion } \\
(\mathrm{MPa})\end{array}$ & $\begin{array}{c}\text { Residual internal } \\
\text { friction angle }\left({ }^{\circ}\right)\end{array}$ & $\begin{array}{c}\text { Residual } \\
\text { cohesion } \\
(\mathrm{MPa})\end{array}$ & $\begin{array}{c}\text { Normal } \\
\text { stiffness } \\
(\mathrm{MPa} / \mathrm{m})\end{array}$ & $\begin{array}{c}\text { Shear } \\
\text { stiffness } \\
(\mathrm{MPa} / \mathrm{m})\end{array}$ \\
\hline Bedding & 27 & 0.15 & 27 & 0.05 & 103808 & 10380 \\
Joint & 25 & 0.12 & 25 & 0.03 & 95000 & 9500 \\
\hline
\end{tabular}

The three caverns are arranged in parallel, and the spacing is $40 \mathrm{~m}$ and $30 \mathrm{~m}$ respectively. The outline dimensions of main power house, main-transformed cavern and tailrace surge cavern are $177.5 \mathrm{~m} \times 25.5 \mathrm{~m} \times$
$57.5 \mathrm{~m}, \quad 153.5 \mathrm{~m} \times 19.5 \mathrm{~m} \times 21.8 \mathrm{~m}$ and $122.4 \mathrm{~m} \times 8 \mathrm{~m} \times 20.3 \mathrm{~m}$ (length $\times$ width $\times$ height) respectively. And the excavation is carried out step by step. 
According to geological information, the bedding angle is $-15^{\circ}$, the spacing is $5 \mathrm{~m}$, and the joint angle is $31.8^{\circ}$, the spacing is $9 \mathrm{~m}$. The grades of surrounding rocks are $40 \sim 80$, and the spacing between the structural planes is $2 \sim 10 \mathrm{~m}$. Therefore, this calculation assumes that the spacing of the joint group is $5 \mathrm{~m}$, the extension length of the structural plane is $10 \mathrm{~m}$, and the connectivity is 0.8 . The model is shown in Figure 2, whose size are all about 5 times larger than the study object. The boundary conditions are taken as displacement constraints, the upper and lower portions are vertical displacement constraint, and the left and right are horizontal displacement constraint, and the calculation model takes into account the step-by-step excavation sequence.

To study the residual strength of rock mass and structural plane influence to deformation and stability of excavation caverns, the calculation includes three plans. Ideal elastic-plastic constitutive are adopt to rock mass and structural plane in plan 1, ideal elastic-plastic stress-strain softening model only uses in rock mass in plan 2, and the softening model are adopt to rock mass and structural plane in plan 3 , which means the residual strength is considered in the calculation.

\section{Calculation results analysis}

According to the calculation of the three plans, the displacement vector diagram of the underground cavern excavation in layered rock mass is shown in Figure 3, shear slip and deformation is mainly along the structural surface. It can be seen that the mechanical characteristics of the structural plan play a major role in controlling the stability of the rock mass. Due to the existence of the fault, the stress (Figure 4 and Figure 5 ) suddenly changes, there are localized stress concentration areas around the three caverns, mainly on the left side of the floor and on the right side of the roof.

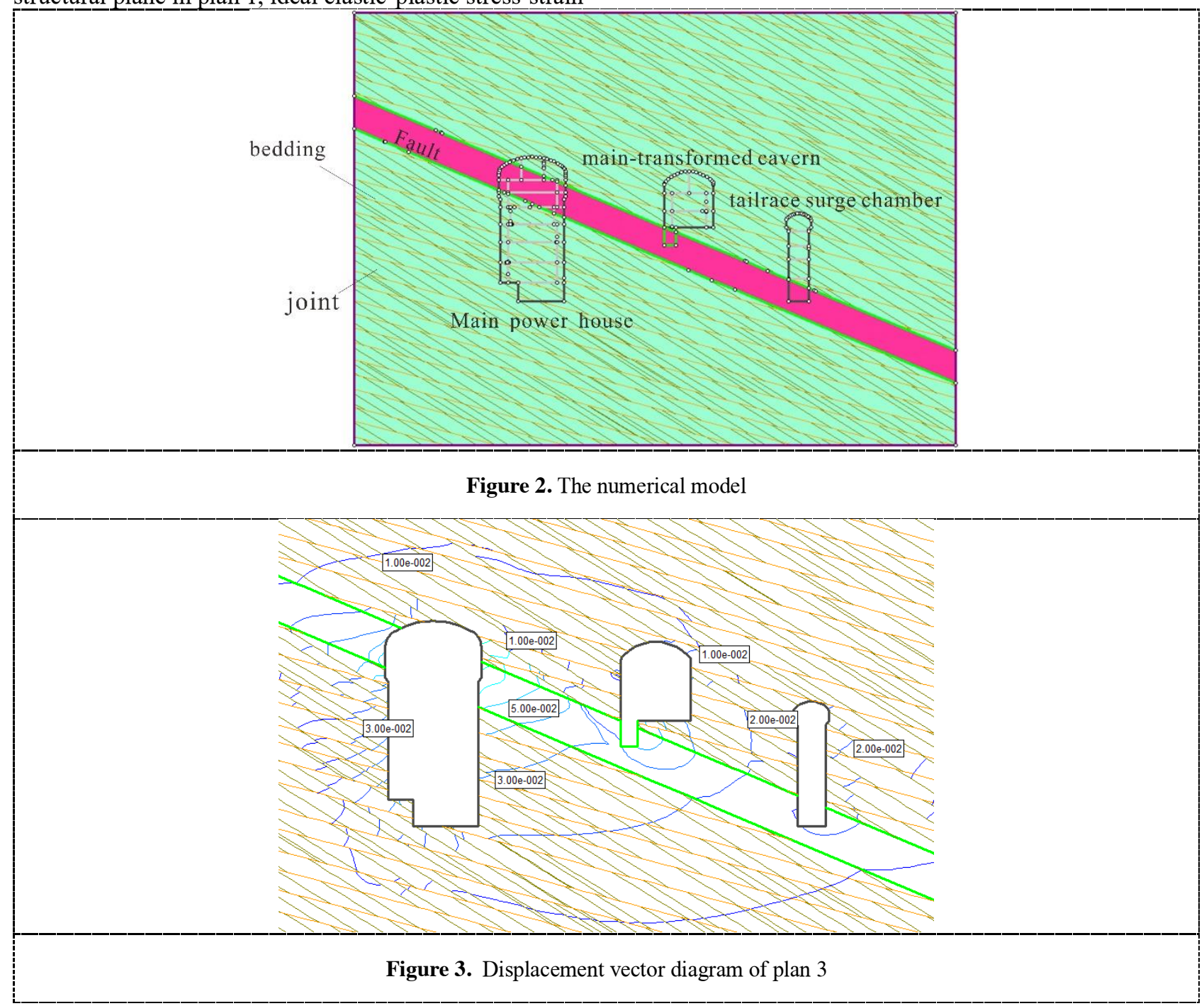




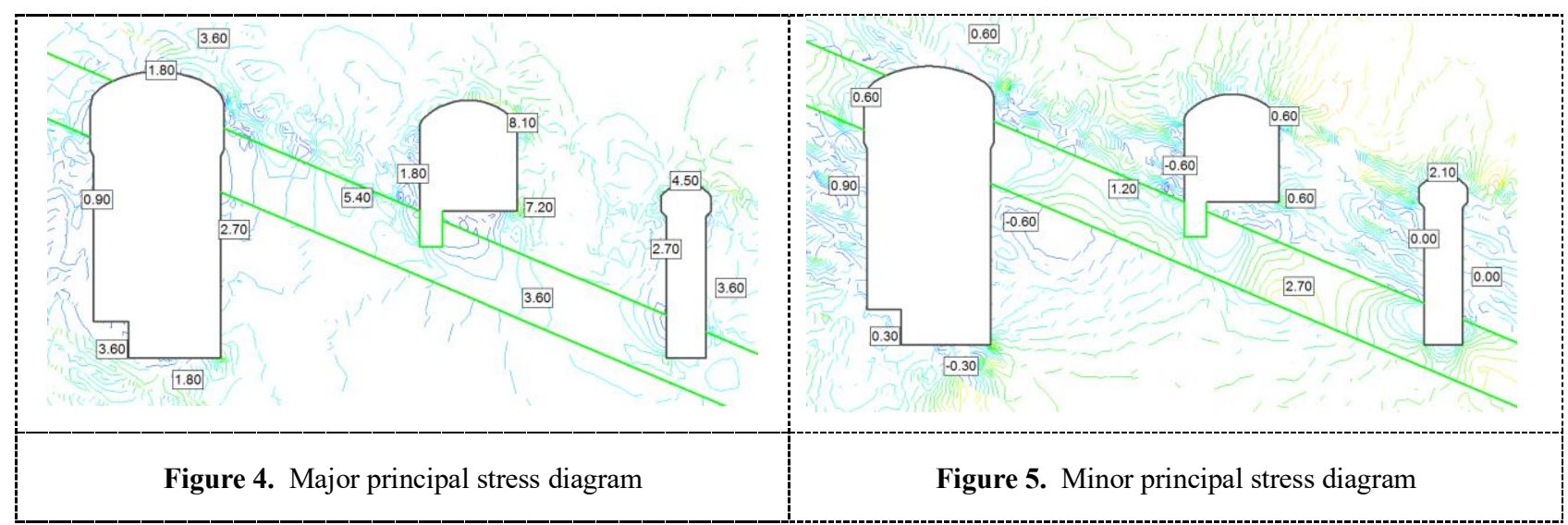

To compare the effect of excavation relaxation on deformation, the ideal elastic-plastic constitutive and stress-strain softening model are adopting to rock mass in plan 1 and plan 3 respectively, and the yield element diagrams are shown in Figure 6 and Figure 7. By comparing the results of the two plans, it can be seen that although the yield zones of the two are all distributed along the structural plane and fault, the yield range of considering the rock mass and structural plane weaken is larger, especially between the main-transformed cavern and tailrace surge cavern. Relative to the yield zone height of $5.78 \mathrm{~m}$ of the main factory building vault in plan 1 , it reaches $8.20 \mathrm{~m}$ in plan 3 . These shows that the excavation

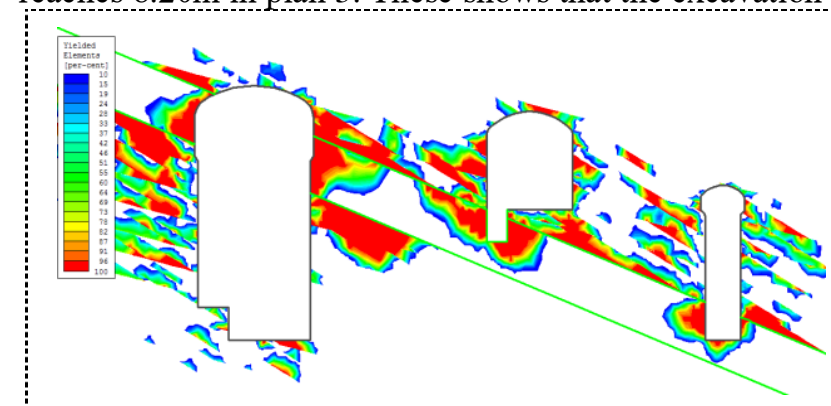

Figure 6. Yield element diagram of plan 1 relaxation has an important influence on the determination of the yield zone and even the support range.

The total displacement with the stage variation curve is shown in Figure 8. According to the calculation results of the three plans, the total displacement increased in turn, and the overall trend is the same, they all stabilized after the 12th step of excavation. The displacement of plan 3 which structural plan also adopted the stress-strain softening model increase rate is significantly larger than plan 2, which indicates that the weaken of structural plane strength has a greater impact on the deformation after excavation.

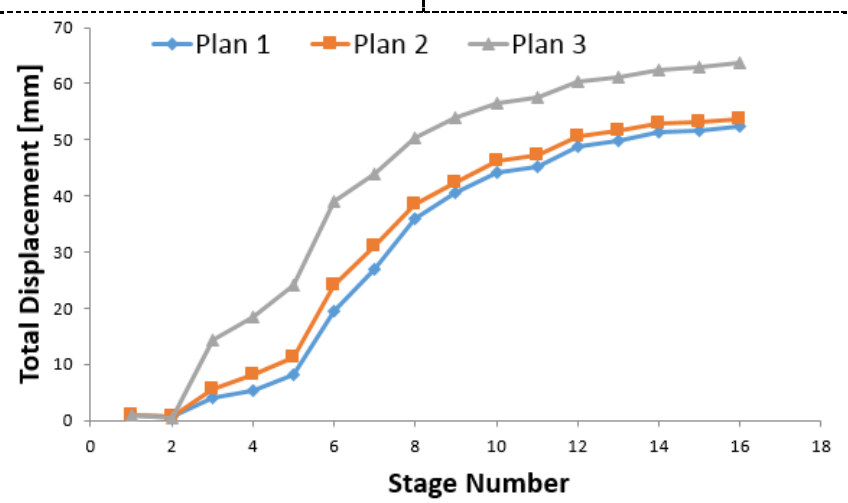

Figure 8. Total displacement with the stage variation curve

\section{Conclusion}

The calculation results of underground cavern excavation relaxation in layered rock mass shows that shear slip and deformation is mainly along the structural surface, which means the mechanical characteristics of the structure surface play a major role in controlling the stability. Although the calculation results have the same trend in the three plans, the displacement and yield zone value of plan 
3 are significantly larger than other two, which adopts stress-strain softening model of both rock mass and structural plan. It shows that the considering the residual strength method is more suitable for the calculation of layered rock mass excavation and relaxation. In this way, the yield zone and support area can be determined better, and then the engineering practice can be guided reasonably.

\section{Acknowledgments}

This work was financially supported by the major science and technology project of Northwest Engineering Corporation Limited, Power China.

\section{References}

1. E. Alonso, L.R. Alejano and F. Varas: submitted to International Journal for Numerical \& Analytical Methods in Geomechanics (2003).

2. J.F. Zou, C. Li and F. Wang: submitted to Computers \& Geotechnics (2017).

3. E. Zou, L.R. Alejano and F. Varas: submitted to International Journal for Numerical Analytical Methods in Geomechanics (2003).

4. S. Wang, X. Yin and H. Tang: submitted to International Journal of Rock Mechanics \& Mining Sciences (2010).

5. Q. Fang, H. Song and D. Zhang: submitted to International Journal for Numerical \& Analytical Methods in Geomechanics (2015). 